\title{
Biocatalytic degradation of selected tobacco chemicals from mainstream cigarette smoke using Croton megalocarpus seed husk biochar
}

Alfayo K. Maiyo ${ }^{1,3}$, Joshua K. Kibet ${ }^{2^{*}}$ (D) and Fredrick O. Kengara ${ }^{1,3}$

\begin{abstract}
Background: Mainstream cigarette smoke contains a complex array of toxic chemicals which can cause irreparable harm to the lungs and most organs in the biological landscape. Attempts to reduce harmful by-products in mainstream cigarette smoke have received little attention although various researchers have proposed the use of catalysts, zeolites and filter modifications. In this study, the bio-degradation of selected tobacco chemicals in a commercial cigarette (MM-R) and a local cigarette (RR-M) is investigated.

Methodology: Croton megalocarpus (C. megalocarpus) seed husk was ground into powder before pyrolysis at $550^{\circ} \mathrm{C}$ to form biochar. The cigarette filter was treated with C. megalocarpus seed husk biochar as an adsorbent in order to degrade tobacco chemicals such as benzene and phenol. Specially designed smoking apparatus consistent with standard procedures for cigarette smoking was used to simulate cigarette smoking. Model tobacco chemicals—benzene and phenol-were characterized using low-resolution electron impact mass spectra on a liquid chromatograph hyphenated to a mass spectrometer. The overall concentration of tobacco chemicals with puff time was screened using a UV-visible spectrometer.

Results: The rate constants for the removal of benzene from treated MM-R and RR-M cigarettes were $0.123 \mathrm{~s}^{-1}$ and $0.0759 \mathrm{~s}^{-1}$, respectively, while the rate constants for the removal of phenol from the model cigarettes were $0.125 \mathrm{~s}^{-1}$ and $0.163 \mathrm{~s}^{-1}$, respectively. For MM-R and RR-M cigarettes, the per cent reduction for benzene was 14.79 and 19.88 while that of phenol was 10.62 and 25.80, respectively. The reduction of benzene at $15 \mathrm{~s}$ puff time for MM-R cigarette was $55.91 \%$ while the reduction of phenol at the same puff time is $37.25 \%$. Also, the reduction in the concentration of benzene and phenol for RR-M model cigarettes was $22.89 \%$ and $66.19 \%$, respectively, at the same puff time. The UVVis data show overall reduction in tobacco chemicals with increase in residence time.
\end{abstract}

Conclusion: The results reported in this study showed that C. megalocarpus seed husk biochar is a promising biocatalyst that can be incorporated into the cigarette filter in order to degrade tobacco chemicals in mainstream cigarette smoke. This is a very important finding towards harm reduction and tobacco reform policy.

Keywords: Mainstream cigarette smoke, Biocatalyst, Biochar, Phenol, Toxic, Rate constant

*Correspondence: jkibet@egerton.ac.ke

${ }^{2}$ Department of Chemistry, Egerton University, Njoro, Kenya

Full list of author information is available at the end of the article

\begin{abstract}
Background
Mainstream cigarette smoke (MCS), commonly referred to as the smoke inhaled by a smoker through the cigarette filter, penetrates directly into the lung tissues and affects the biological landscape (Kamissoko et al. 2019). MCS comprises more than 7000 chemical constituents that include complex mixtures, gases and particulates formed
\end{abstract}


through incomplete combustion of tobacco (Cui et al. 2019). Approximately 150 of these components are wellknown toxicants that contain molecular species such as phenol and benzene. The phenolic compounds in cigarette smoke are formed from the thermal degradation of polyphenols, chlorogenic acid and lignin while benzene may be generated by the combustion of organic matter in tobacco (Kibet et al. 2015). MCS contains 35-70 ppm benzene, but even higher concentrations of benzene are generated from other tobacco products such as water pipes, cigarillos and pipe tobacco (Abplanalp et al. 2017). Many years after harmful effects of tobacco on human health were first documented; tobacco smoking remains one of the major global causes of death and disability (Flor et al. 2021). Therefore, over the last decade, there has been active interest in the analysis and identification of toxic tobacco smoke chemicals.

There are good reasons to study the impact of individual chemical components of main stream cigarette smoke, including the identification of individual chemicals that may induce maximum harm on human health, and which should be prioritized for risk reduction measures and evaluation (Bos et al. 2021). A great number of researchers and proponents of tobacco control including the World Health Organization (WHO) have been faced with serious questions on whether there is a way tobacco fatalities, currently in excess of 8 million deaths per year, can be reduced. A vaccine against tobacco use has also been suggested (Chaaya et al. 2019; King and Graffunder 2018). The tobacco control vaccine has been designed as a preventive measure to reduce tobacco use and tobaccorelated illnesses and deaths. This has been complemented by the development of strong tobacco control policies such as mQuit programme which has been successfully applied in Malaysia and is currently being replicated elsewhere in other countries (Hassan et al. 2018). More importantly, the World Health Organization Framework Convention on Tobacco Control (WHO-FCTC) recommends a range of evidence-based tobacco control measures. Countries that approve of these policies are obliged to implement with the aim of preventing and controlling the tobacco epidemic (Chaaya et al. 2019). Introduction of punitive taxes on tobacco products is another approach towards reforming tobacco control policy aimed at making tobacco unaffordable. Nonetheless, the degradation of tobacco toxins from a chemical standpoint has largely been ignored in tobacco reform policies. This would perhaps be the most effective method towards harm reduction, which is the motivation underpinning this study. In this work, a biocatalyst-C. megalocarpus seed husk biochar-is used to degrade tobacco chemicals in mainstream cigarette smoke with remarkable results. Two model chemicals in mainstream cigarette smoke-benzene and phenol-are critically examined in this work.

Phenolic compounds, in particular phenol, o-cresol, $m$-cresol, $p$-cresol, catechol, resorcinol and hydroquinone, have been identified in mainstream cigarette smoke (Bak et al. 2015). Although these molecular species have flavours and add aroma characteristics in cigarettes, they are potentially toxic and carcinogenic (Schubert et al. 2015). Previous studies have shown that phenol and cresols are cardiovascular toxins, while hydroquinone, catechol and alkyl catechols are tumour promoters that increase invasion and metastasis (Cai et al. 2019). Benzene, apart from being a key player in the development of respiratory diseases has been listed as a possible human carcinogen by the National Toxicology Program (NTP) and the International Agency for Research on Cancer (IARC) (Ferrero et al. 2017; Rodriguez-Acevedo et al. 2020).

During cigarette smoking, cigarette smoke compounds nucleate during tobacco burning to form various sizes of particulates typically in the sub-micron level. These are readily inhaled into the respiratory tract and lungs of cigarette smokers thus causing cell and organ injuries (Baker 2006; Cui et al. 2019). The complexity of smoke mainly results from the multifarious chemical composition of tobacco together with multiple thermolytic processes such as combustion, dehydration, volatile release and pyrolysis (Eaton et al. 2018). Generally, pyrolysis can be defined as the direct decomposition of an organic matter in order to obtain an array of reaction products without or with a limited supply of oxygen (Khuenkaeo et al. 2021; Kibet et al. 2012). Tobacco pyrolysis is used to obtain information about the behaviour of the cigarette smoking process and the smoke generated which occurs under dynamic conditions representative of actual tobacco burning during cigarette smoking (Busch et al. 2012; Calabuig and Marcilla 2021).

There have been numerous attempts to reduce the concentration of toxic chemicals in mainstream cigarette smoke by utilization of various filters and selection of tobacco with lower levels of chlorogenic acid (Shifflett et al. 2017). The efforts to reduce these harmful by-products remain futile since they have small particulate size (near ultrafine nature) which pass through the cigarette filter and penetrate deeper into the lungs of the cigarette smoker thus causing damage to the respiratory landscape (Ren et al. 2016; Song et al. 2017). Cigarette filters only help in blocking the largest tar particulates (Song et al. 2017). As a result, various proposals have been suggested. For example, Marcilla et al. (2016) proposed a new burning system while other researchers added catalysts to tobacco or the tobacco filter tip with the aim of minimizing cigarette chemicals in mainstream cigarette 
smoke. Among the first attempts, the compound with the formula $\mathrm{M}_{2} \mathrm{M}^{\prime} \mathrm{RuO}_{6}$ was applied to degrade tobacco toxins, where $\mathrm{M}$ is a divalent metal, $\mathrm{M}^{\prime}$ is a trivalent rare earth metal, $\mathrm{Ru}$ has a valence of $5, \mathrm{M}$ and $\mathrm{M}^{\prime}$ are capable of forming a perovskite lattice with the Ru ions (Marcilla et al. 2016). According to Marcilla et al. (2016), this compound when incorporated into the cigarette filter enhances the reduction of $\mathrm{NO}$ and $\mathrm{CO}$ from tobacco smoke into less harmful by-products. In the same way, the adoption of metallic catalysts such as vanadium pentoxide, molybdenum trioxide or rhodium oxides to produce less-toxic substances such as $\mathrm{CO}_{2}$ and water have been used previously (Kennedy et al. 2013; Shen et al. 2014).

The use of nanoparticles such as $\mathrm{Fe}_{2} \mathrm{O}_{3}$ and $\mathrm{TiO}_{2}$ doped with $\mathrm{Zr}, \mathrm{Pb}$ and $\mathrm{Mn}_{2} \mathrm{O}_{3}$ increased the conversion of $\mathrm{CO}$ to $\mathrm{CO}_{2}$ in mainstream cigarette smoke as suggested in the literature (Jing et al. 2016; Murniati et al. 2015). Nonetheless, the use of $\mathrm{Pb}$ as a catalytic dopant can be detrimental to human health and should be avoided. Luo et al. (2015) described the use of a single catalyst based on iron (II) oxide nanoparticles generated in situ when the cigarette is burning and is capable of enhancing the conversion of $\mathrm{CO}$ and $\mathrm{NO}$ to $\mathrm{CO}_{2}$ and $\mathrm{N}_{2}$, respectively. On the other hand, potassium organic salts can be used as additives in cigarettes with the capability of minimizing the emission of $\mathrm{CO}$, nicotine and nicotine-free dry particulate matter (NFDPM) (Brinkman et al. 2020; Ding et al. 2017). Moreover, Marcilla et al. (2015) used three commercial zeolites (HUSY, Hb, HZSM-5) and a synthesized Al-MCM-41 catalyst on commercial tobacco cigarettes to reduce the yield of some toxic chemicals present in mainstream cigarette smoke. Mesoporous Al-MCM-41 catalyst reduced $\mathrm{CO}$ by $23 \%$, nicotine and total particulate matter (TPM) in the traps reduced by $41 \%$ while synthesized Al-MCM-41 could reduce the concentration of most toxic and carcinogenic compounds in mainstream cigarette smoke significantly (Marcilla et al. 2015). Nonetheless, the use of biochar was incorporated as an adsorbent in the cigarette filter targeting numerous harmful pyrolysis products including phenols and benzene. This procedure is a promising non-harmful technique which may change the future cigarette significantly and possibly mitigate health problems caused by cigarette smoking.

A brief account on the degradation characteristics of biochar is therefore very important. Generally, biochar is a pyrogenic black carbon derived from the pyrolysis of biomass feedstocks, including agricultural and forest residuals, in limited oxygen (Sun et al. 2014; Ambaye et al. 2021). The resulting solid is rich in carbon and presents a promising adsorption ability which allows it to remove organic toxins from complex matrices such as tobacco smoke (Ambaye et al. 2021). The adsorption mechanism of biochar to remove toxic chemicals in a matrix can be attributed to electrostatic inter-actions, ion exchange, pore filling and precipitation (Ambaye et al. 2021). Biochar has high specific surface area, developed pore structure, abundant surface functionalities and of low cost compared to inorganic catalysts (Liang et al. 2021; Tan et al. 2015). Furthermore, plantbased biochar has a large content of carbon and oxygen elements which can produce various functional groups $(-\mathrm{COOH},-\mathrm{C}-\mathrm{O}-\mathrm{R},-\mathrm{C}-\mathrm{OH})$ on the surface of biochar; these groups can serve as additional active sites to improve the removal efficiency of toxins (Liang et al. 2021; Takaya et al 2016). In this work, Croton megalocarpus seed husk was used to prepare biochar because it is a by-product of Croton oil seeds. In addition, wood-based biochar-the type applied herein-has some advantages such as high surface area and lower ash content compared to other biochars (Tomczyk et al. 2020).

\section{Methods}

In this study, we describe for the first time a method for reducing the amount of benzene and phenol in mainstream cigarette smoke using a biocatalyst-Croton megalocarpus (C. megalocarpus) seed husk biochar. Ideally, smoke generation by a smoking machine should mimic actual vaping conditions of a human smoker. Puffing regimens are related to at least three key parameters: puff volume, puff duration and puff frequency (Beauval et al. 2019). The smoking approach applied in this study is that proposed by the International Organization for Standardization (ISO), 2015 (IS0 3308) (Gasparyan et al. 2018). The protocol includes: $35 \mathrm{~mL}$ puff volume; puff duration: $2 \mathrm{~s}$; puff frequency: one puff per $60 \mathrm{~s}$ (Busch et al. 2012; Jablonski et al. 2019). In this study, the puff duration was adjusted at various residence times of 2, 5, 10 and $15 \mathrm{~s}$ for both the commercial cigarette (MM-R) and the local cigarette (RR-M). A requirement of these procedures is the reproduction of the basic phenomena of human smoking in the form of short puffs with longer delays between puffs. The smoking apparatus used herein was designed and fabricated in our laboratory.

\section{Reagents}

Analytical grade methanol and acetonitrile were purchased from Merck, Germany, through Gel sap Laboratory supplies in Nairobi, Kenya. Analytical grade standards phenol (> 99\%) and benzene ('99\%) were imported from Merck, Germany, through Kobian Laboratory suppliers in Kenya. The reagents were used without further treatment. 


\section{Collection and preparation of biochar from Croton megalocarpus seed husk}

The licence and permit to conduct this research were obtained from the National Commission for Science, Technology and Innovation (NACOSTI) - the research organization in charge of licensing and monitoring all research activities in Kenya. The research licence no. NACOSTI/21/11440 was allocated for this work. C. megalocarpus seeds were locally obtained from Kessup forest in Elgeyo/Marakwet County at an altitude of about $2400 \mathrm{~m}$ above sea level. The husks were washed after the seeds were removed from their shells, dried in an oven at $110{ }^{\circ} \mathrm{C}$ for $4 \mathrm{~h}$, ground to powder using a laboratory mill and sieved using 40 micron sieve (Fig. 1a). C. megalocarpus husk seeds powder was eventually wrapped in an aluminium foil and micro-heated using a Gallenkamp Tactical 308 Sizel Muffle furnace maintained at $550{ }^{\circ} \mathrm{C}$ for 45 min resulting in the biochar shown in Fig. 1b.

\section{Sample preparation}

Commercial and traditional (local) cigarettes were purchased from retail outlets in Eldoret City, Kenya, and coded MM-R and RR-M, respectively, before conditioning at room temperature under constant humidity in accordance with tobacco smoking procedure developed by Busch et al. (2012). For the treated cigarettes (MM-R and RR-M): the cigarette filter was carefully removed, then $1 \mathrm{~cm}$ length of the filter was removed at the middle so that approximately $0.5 \mathrm{~cm}$ was left out on both ends of the filter. Consequently, dried powder of C. megalocarpus seed husk biochar weighing approximately $0.24 \mathrm{~g}$ was carefully sandwiched in the filter as shown in Fig. 2.

Smoking apparatus used in this work (Fig. 3) was designed and fabricated in our laboratory. The model cigarettes were smoked according to the ISO 4387 smoking procedure: $35 \mathrm{~mL}$ puff volume with $2 \mathrm{~s}$ residence time every $60 \mathrm{~s}$ (Wright 2015). For kinetic purposes, the residence time was varied from 2 to $5 \mathrm{~s}$, and from 10 to $15 \mathrm{~s}$ in order to simulate puffing regimes exhibited by various cigarette smokers. A cigarette stick was fixed at the tip end of a rubber tubing and lit using a cigarette
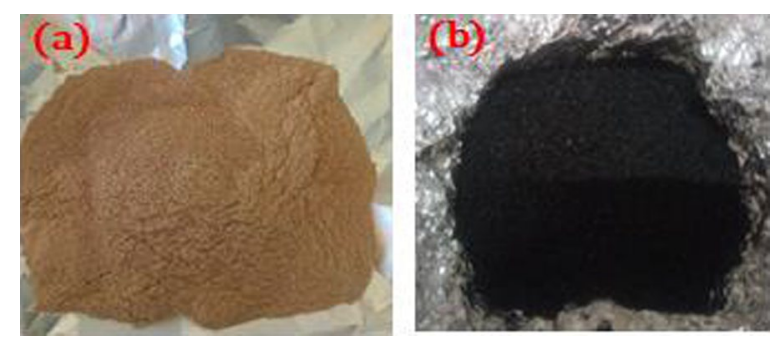

Fig. 1 Croton megalocarpus seed husks powder (a) and $\mathbf{b}$ its corresponding biochar

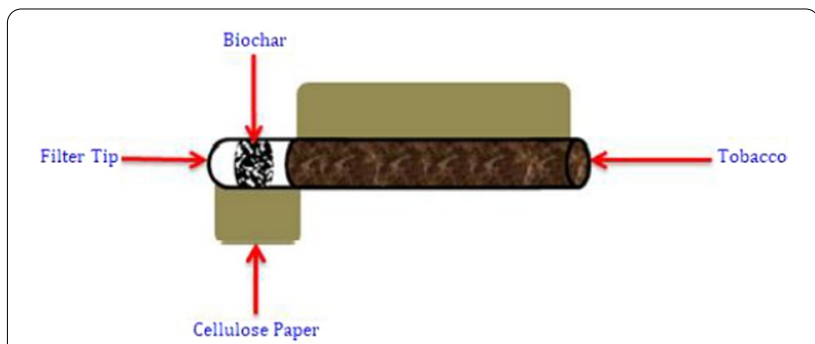

Fig. 2 Cigarette rod treated with C. megalocarpus seed husk biochar-Modified from Jebet et al. (2017)

lighter according to the protocol adopted by Jebet et al. (2017). A syringe was used to draw in air to ensure constant burning of the tobacco cigarette (Jebet et al, 2017). The cigarette was smoked into a mixture of methanol and acetonitrile-ratio of $7: 3$ in a $250-\mathrm{mL}$ volumetric flask via well-fitted glass tubes connected to rubber tubes as shown in Fig. 3. For every residence time, five cigarettes were smoked on average and experiments conducted in replicates in order to enhance reproducibility of data.

\section{Chromatographic determination of benzene and phenol from MM-R and RR-M cigarettes}

The analytical procedure followed was that used by Kibet et al. (2017). The analysis of benzene and phenol from cigarette pyrolysate was carried out using low-resolution electron impact mass spectra on a Quadruple Time of Flight (QTOF) Premier-Water Corp liquid chromatograph coupled to a mass selective detector. The model of the electrospray ionization (ESI) used in this work was Alliance 2695-Quattro ultima with an in-line degasser and a millennium 32 data processor. For separation, a $\mathrm{C} 18$ column stable at $30^{\circ} \mathrm{C}$ was used. The mobile phase was a binary of $70 \%$ acetonitrile and $30 \%$ methanol at a flow rate of $0.6 \mathrm{~mL} \mathrm{~min}^{-1}$. The sample injection volume was $5 \mu \mathrm{L}$. The signals of molecular products investigated were identified by comparing their retention times with

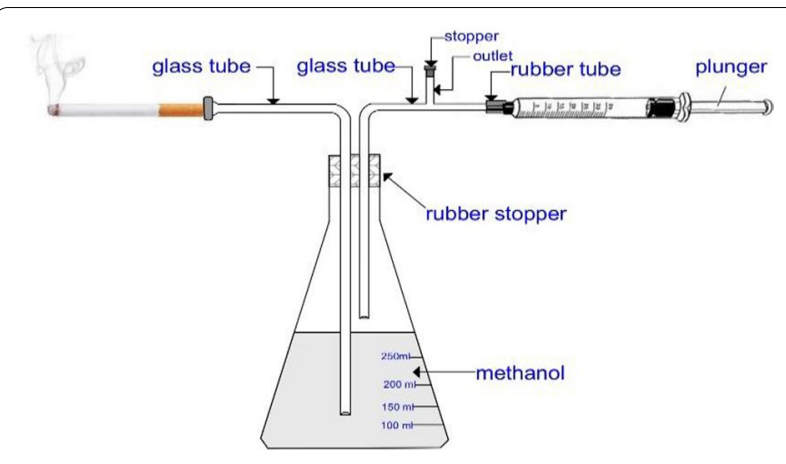

Fig. 3 Assembly of cigarette smoking apparatus 
those of their respective standards (chromatograms of pure compounds). The chromatograms were run through the NIST library database and Agilent's Chemstation as additional tools to ensure the correct compounds-benzene and phenol-were identified. The data reported in this work are an average of three replicates.

\section{UV-Vis analysis of tobacco chemicals in MM-R and RR-M cigarettes}

The average formation of tobacco chemicals from MM-R and RR-M cigarettes was determined experimentally at various puff times using laboratory designed apparatus as shown in Fig. 3. The characteristic absorbance for the formation of tobacco chemicals at various puff times was plotted as a function of average maximum wavelength. Maximum absorbance of tobacco chemicals occurred in the range of 240 to $250 \mathrm{~nm}$. Methanol was used as a blank in UV-Vis analysis. UV-Vis spectrophotometer $\mathrm{K} 7 / \mathrm{K} 9$ series was used to obtain the data reported herein.

\section{Kinetics of removal of tobacco chemicals using biochar}

Based on the assumptions made with respect to this study in kinetic modelling of tobacco chemicals, the rate of formation of phenol and benzene is expected to dominate the rate of destruction. For this reason, the rate of removal of tobacco chemicals is expected to be lower than the rate of formation of these chemicals. This observation is consistent with the data reported in this work and elsewhere in the literature in the case of the destruction of nicotine in mainstream cigarette smoke (Kibet et al. 2016). Therefore, to determine the rate constant $(k)$, the concentration of molecular products during cigarette smoking is monitored under varying residence times $(2 \mathrm{~s}, 5 \mathrm{~s}, 10 \mathrm{~s}$ and $15 \mathrm{~s})$ and expressed mathematically as pseudo-first-order rate law according to Eq. (1).

$$
\text { Rate of reaction }=\frac{\Delta C}{\Delta t}=k C_{\mathrm{O}}
$$

where $C$ is the concentration of phenol or benzene in mainstream cigarette smoke. Conventionally, the differential rate law for the final product was re-arranged to have the general form of a straight line according to Eqs. (2) and (3), respectively.

$$
\ln \left(C / C_{\mathrm{O}}\right)=-K t
$$

where " $\ln$ " is the natural logarithm, $C_{0}$ is the initial concentration of phenol or benzene, and $C$ is the concentration of any of the chemical species at any given time.

$$
\ln C=-K t+\ln C_{\mathrm{O}}
$$

Therefore, the graph of natural logarithm (ln) of the concentration $C$ versus time $t$ is consistent with firstorder rate law. Ideally, the slope of the curve gives the rate constant $(k)$ whereas the $y$-intercept can be used to compute the original concentration of the molecular species under investigation.

\section{Results}

Kinetics destruction of benzene and phenol in mainstream cigarette smoke

To mimic actual cigarette smoking conditions, smoking apparatus were designed according to ISO 3308:2015 standards (Busch et al. 2012). Smoking residence times $(2,5,10$ and $15 \mathrm{~s})$ representing actual cigarette smoking conditions were explored. The destruction kinetics of phenol and benzene were critically examined for model cigarettes treated with $C$. megalocarpus seed husk biochar (MM-R and RR-M) and corresponding untreated cigarettes $M M-R$ and $R R-M$ from which the removal rate constants were determined. The removal kinetics of benzene in MM-R and RR-M cigarettes, gave the rate constants as $0.120 \mathrm{~s}^{-1}$, and $0.0759 \mathrm{~s}^{-1}$ for the treated, and $0.0759 \mathrm{~s}^{-1}$ and $0.076 \mathrm{~s}^{-1}$ for the untreated, respectively (Fig. 4c, d).

On the other hand, the kinetics of phenol in MM-R and RR-M cigarette gave the removal rate constants as $0.125 \mathrm{~s}^{-1}$ and $0.163 \mathrm{~s}^{-1}$ (treated) and $0.100 \mathrm{~s}^{-1}$ and $0.112 \mathrm{~s}^{-1}$ (untreated), respectively (Fig. 5a, c). The plots, although an estimation from restricted smoking times are consistent with pseudo-first-order reaction kinetics as shown in Fig. 5a, c and Fig. 5b, d. Figure 5b, d depicts the rate of decay of the concentration of benzene in the two model cigarettes as a function of puff times.

The original amount of benzene and phenol from MM-R and RR-M cigarettes was estimated from the $y$-intercept and is summarized in Table 1 . Interestingly, MM-R and RR-M cigarettes treated with $C$. megalocarpus biochar showed significant reduction in benzene-14.79 for MM-R and $19.88 \%$ for $R R-M$, and for phenol, a reduction of 10.62 for MM-R and $25.80 \%$ for RR-M cigarettes, respectively, was observed. This reveals the effectiveness of $C$. megalocarpus seed husk biochar as an excellent adsorbent and its ability to reduce toxic molecular products in cigarette mainstream smoke especially for benzene and phenol. Consequently, the total percentage reduction of benzene and phenol in traditional (local) cigarette (RR-M) is $\sim 19.88$ and $25.80 \%$, respectively, and is significantly higher compared to the reduction witnessed in the commercial cigarette (MM-R) which is $\sim 14.79$ and $10.62 \%$, respectively. 

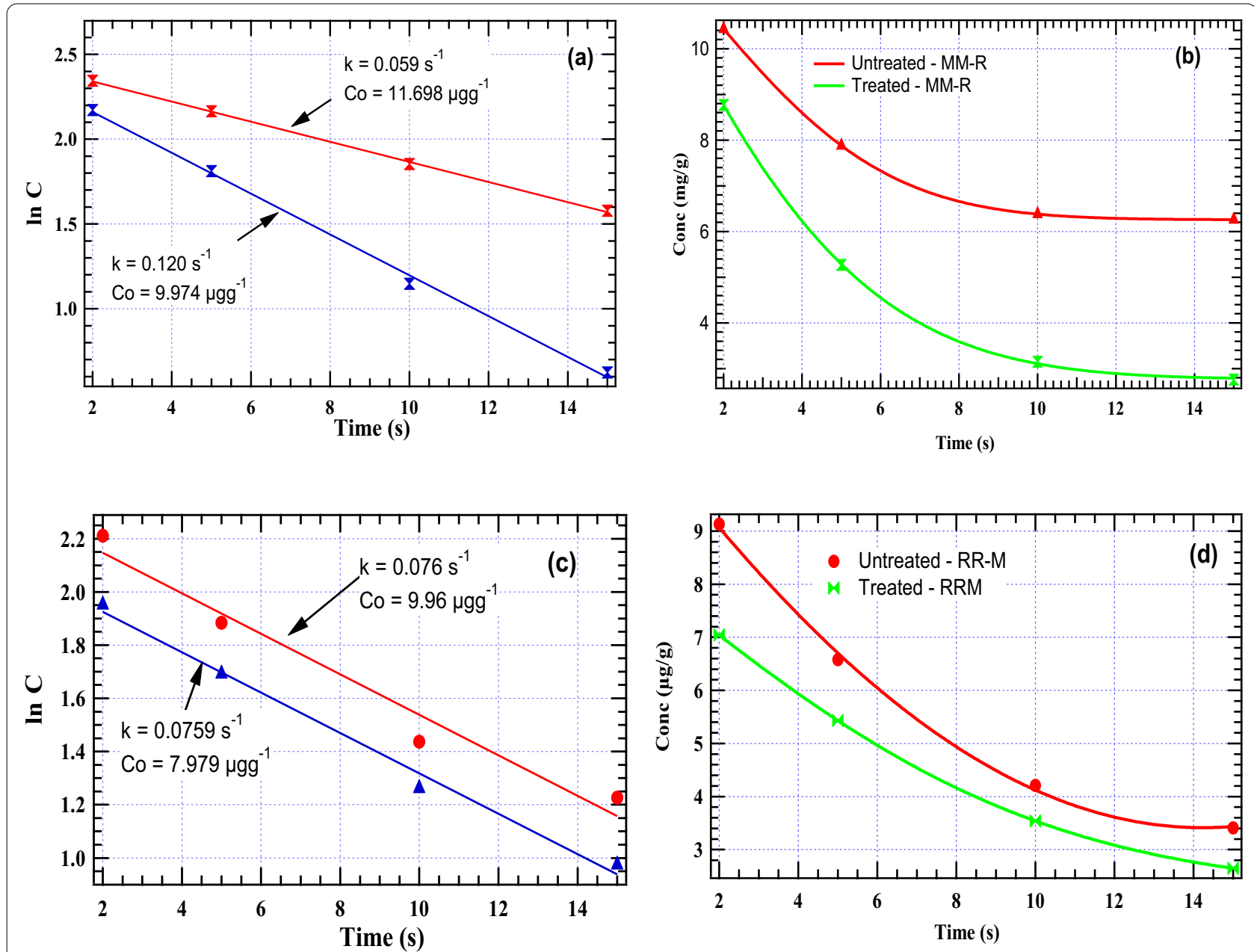

Fig. 4 Kinetics of benzene in MM-R cigarette $(\mathbf{a}, \mathbf{b})$ and kinetics of benzene in RR-M cigarette $(\mathbf{c}, \mathbf{d})$

\section{Effect of residence time on cigarette smoking}

UV-Vis was conducted on cigarette smoke effluent samples and the maximum absorbance averaged for all chemicals in mainstream cigarette smoke is reported in Fig. 6. From the literature, the major chemical in tobacco is nicotine-accounting for $95 \%$ of all alkaloids present in tobacco burning (Kibet et al. 2016; Lisko et al. 2013). Generally, nicotine is also the major chemical in tobacco and may be responsible for the observed maximum absorbance which is consistent with studies conducted by Kibet et al. (2016). The wavelength for tobacco chemicals in general ranged between 240 and $250 \mathrm{~nm}$ with maximum absorbance readings of 0.92 and 0.66 for the untreated and the treated standard cigarette (MM-R) as shown in Fig. 6a, b, respectively, while the absorbance readings for the untreated local cigarette (RR-M) was 0.70 and 0.53 according to Fig. $6 c$, d, respectively.
A specific study on per cent reduction in benzene and phenol was conducted using a liquid chromatograph coupled to a mass spectrometer (LC-MS) and the data are presented in Table 2. Remarkably, the results presented reveal the catalytic activity of $C$. megalocarpus seed husk biochar in the reduction of pyrolytic by-products in mainstream cigarette smoke. For each resident time (2, 5, 10 and $15 \mathrm{~s}), \mathrm{MM}-\mathrm{R}$ cigarette showed a reduction ranging from 15.96 to $55.91 \%$, while for RR-M cigarette; reduction range was $15.91-22.89 \%$ for benzene. On the hand, a reduction range of $14.81-37.25 \%$ and $33.88-66.19 \%$ for phenol was realized for MM-R and RR-M cigarettes, respectively, as demonstrated in Table 2 and Fig. 7.

It is clear from Fig. 7 that as the puff time increases, the degree of destruction of model tobacco chemicals increases. However, the increase is dependent on the type of cigarette and the tobacco chemical investigated. The 

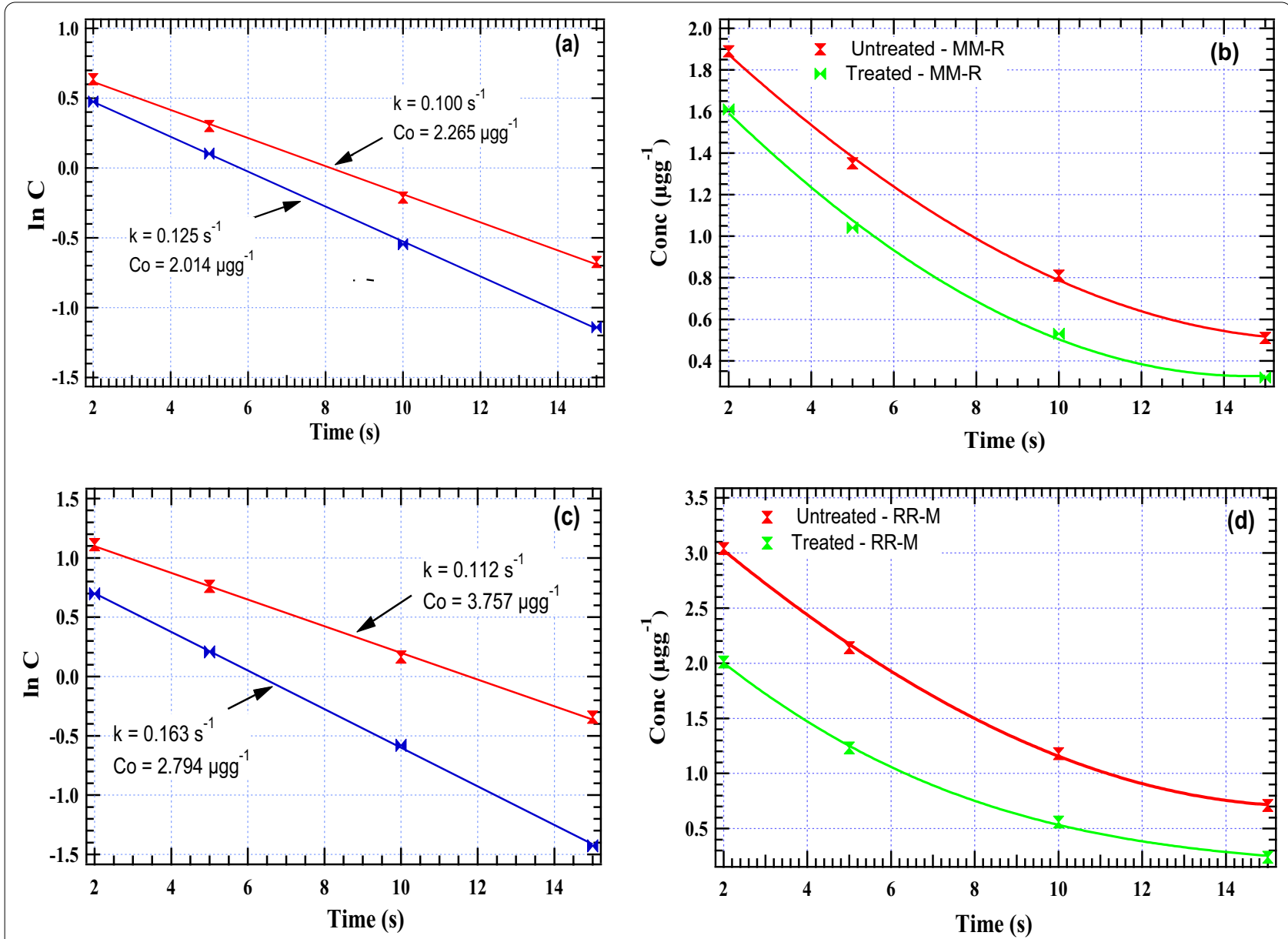

Fig. 5 Kinetics of phenol in MM-R cigarette $(\mathbf{a}, \mathbf{b})$ and kinetics of phenol in RR-M cigarette $(\mathbf{c}, \mathbf{d})$

Table 1 Percent reduction of benzene and phenol in mainstream cigarette smoke for the two model cigarettes

\begin{tabular}{|c|c|c|c|c|c|c|c|}
\hline \multicolumn{4}{|l|}{ Benzene } & \multicolumn{4}{|l|}{ Phenol } \\
\hline \multicolumn{2}{|c|}{ MM-R cigarette } & \multicolumn{2}{|c|}{ RR-M cigarette } & \multicolumn{2}{|c|}{ MM-R cigarette } & \multicolumn{2}{|c|}{ RR-M cigarette } \\
\hline \multicolumn{2}{|c|}{ Concentration $\left(\mu \mathrm{g} \mathrm{g}^{-1}\right)$} & \multicolumn{2}{|c|}{ Concentration $\left(\mu \mathrm{g} \mathrm{g}^{-1}\right)$} & \multicolumn{2}{|c|}{ Concentration $\left(\mu \mathrm{g} \mathrm{g}^{-1}\right)$} & \multicolumn{2}{|c|}{ Concentration $\left(\mu \mathrm{g} \mathrm{g}^{-1}\right)$} \\
\hline Untreated & 11.70 & Untreated & 9.96 & Untreated & 2.26 & Untreated & 3.76 \\
\hline Treated & 9.97 & Treated & 7.98 & Treated & 2.02 & Treated & 2.79 \\
\hline$\%$ Reduction & 14.79 & & 19.88 & & 10.62 & & 25.80 \\
\hline
\end{tabular}

Bold values defined \% Reduction of model tobacco chemical

$M M-R$ standard cigarette, $R R-M$ local cigarette

reduction in benzene for the standard cigarette (MM-R) is higher when compared to the destruction of benzene for the non-standard (local) cigarette (RR-M). On the other hand, the reduction of phenol for the non-standard cigarette increases linearly with increase in the puff time and reaches a maximum at $66.19 \%$.

\section{Discussion}

UV-Vis data are basically qualitative but remarkably corroborate liquid chromatograph (LC) data in the decrease in selected tobacco chemicals-benzene and phenol. The decrease in absorbance under conditions that simulate cigarette smoking ( $2 \mathrm{~s}$ residence time) for the treated 

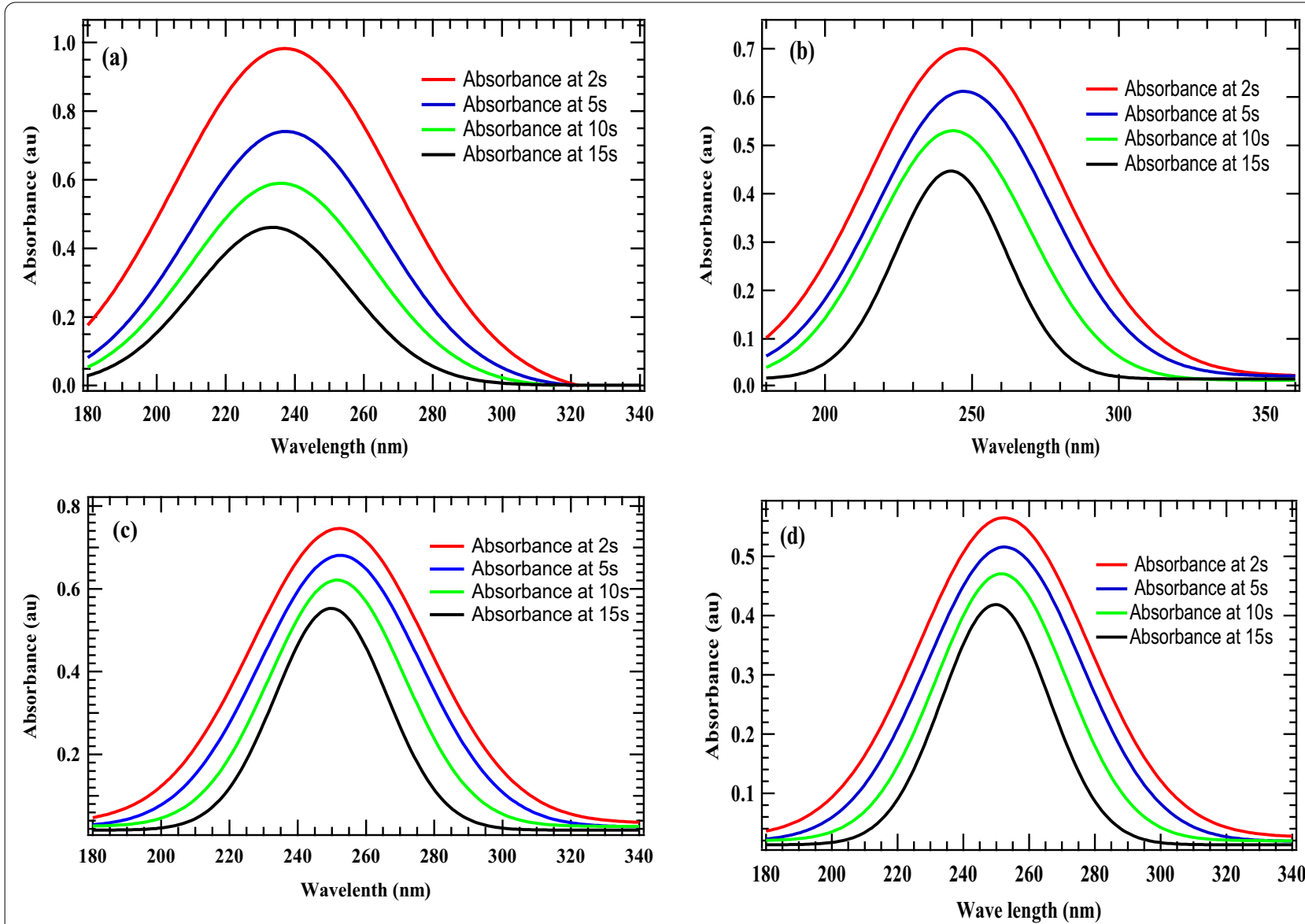

Fig. 6 Absorbance of tobacco chemicals at various puff times: $\mathbf{a}$ untreated and $\mathbf{b}$ treated MM-R and $\mathbf{c}$ untreated and $\mathbf{d}$ treated RR-M cigarettes

Table 2 Percentage reduction of model tobacco toxins-benzene and phenol in cigarette smoke

\begin{tabular}{|c|c|c|c|c|c|c|c|c|c|}
\hline \multirow{2}{*}{$\begin{array}{l}\text { Model smoke toxin } \\
\text { Residence time (s) }\end{array}$} & & \multicolumn{4}{|c|}{ Benzene } & \multicolumn{4}{|c|}{ Phenol } \\
\hline & & 2 & 5 & 10 & 15 & 2 & 5 & 10 & 15 \\
\hline Model cigarette & Nature & \multicolumn{4}{|c|}{ Concentration $\left(\mu \mathrm{g} \mathrm{g}^{-1}\right)$} & \multicolumn{4}{|c|}{ Concentration $\left(\mu \mathrm{gg}^{-1}\right)$} \\
\hline \multirow[t]{2}{*}{ MM-R cigarette } & Untreated & 10.43 & 7.88 & 6.38 & 6.26 & 1.89 & 1.53 & 0.81 & 0.51 \\
\hline & Treated & 8.77 & 5.27 & 3.15 & 2.76 & 1.61 & 1.04 & 0.56 & 0.32 \\
\hline$\%$ Reduction & & 15.96 & 33.12 & 50.62 & 55.91 & 14.81 & 30.86 & 32.03 & 37.25 \\
\hline \multirow[t]{2}{*}{ RR-M cigarette } & Untreated & 9.13 & 6.58 & 4.21 & 3.41 & 3.04 & 2.14 & 1.18 & 0.71 \\
\hline & Treated & 7.04 & 5.43 & 3.54 & 2.65 & 2.01 & 1.23 & 0.56 & 0.24 \\
\hline$\%$ Reduction & & 15.91 & 17.47 & 22.28 & 22.89 & 33.88 & 42.52 & 52.54 & 66.19 \\
\hline
\end{tabular}

Bold values defined \% Reduction of model tobacco chemical

$M M-R$ standard cigarette, $R R-M$ local cigarette

standard cigarette MM-R by $28 \%$ and $33 \%$ for the treated local RR-M cigarette is evidence that C. megalocarpus seed husk biochar can effectively be incorporated into the cigarette filter to minimize toxins that impinge the lungs of the cigarette smoker. Various puff (residence) times gave different absorbance readings. Clearly, there is an overall decrease in absorbance with increase in residence time as shown in Fig. 6. This study has therefore demonstrated a remarkable breakthrough towards harm reduction among the cigarette smoking community. The difference in the reduction efficiencies between the two model cigarettes may be attributed to possible different 

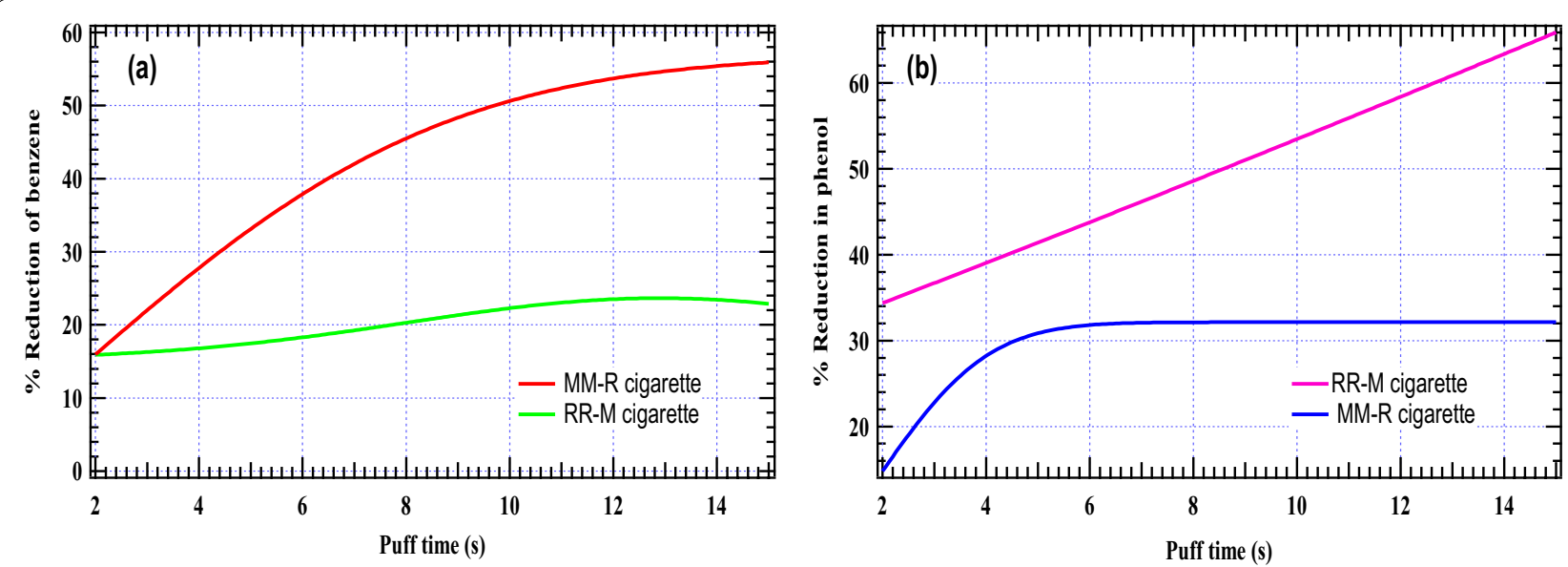

Fig. 7 Comparative destruction of benzene (a) and $\mathbf{b}$ destruction of phenol in MM-R and RR-M model cigarettes as a function puff time

growing conditions and additives (moisturizing agents, preservatives and numerous flavours) during the processing of the commercial cigarette. Nonetheless, additives of varying compositions introduced during cigarette processing may act as catalysts capable of degrading tobacco chemicals during cigarette smoking (Kibet et al. 2016).

The effect on residence time (puff time) was explored and noted that at shorter residence times, the removal of tobacco chemicals was low. For instance, at a residence time of $2 \mathrm{~s}$, the destruction of benzene was $15.96 \%$ for the commercial cigarette MM-R and $15.91 \%$ for the local cigarette RR-M as compared to a reduction of 33.12 and $17.47 \%$ for the commercial (standard) and the nonstandard cigarettes, respectively, at a puff time of $5 \mathrm{~s}$. A similar trend was noted for the destruction of phenol in mainstream cigarette smoke as can be noted in Table 2 . At longer residence times (puff times) the reduction of tobacco toxins increases significantly-in this case, model tobacco compounds (benzene and phenol). The reduction of benzene at $15 \mathrm{~s}$ puff time for MM-R cigarette was $55.91 \%$ while the reduction of phenol at the same puff time is $37.25 \%$. Also, at longer puff times (15 s), the reduction in the concentration of benzene and phenol for RR-M model cigarettes was $22.89 \%$ and $66.19 \%$, respectively. For the standard cigarette, the reduction in phenol increases significantly from 2 to $5 \mathrm{~s}$ before slowly increasing for the 10 and 15 s puff times, reaching a maximum of $22.89 \%$. This means that at 15 s residence time, the destruction of phenol in the local cigarette is $\sim 1.8$ times that reported for the standard cigarette. Notably, the degradation of benzene at the same residence time for the standard cigarette is $\sim 2.5$ times that of the local cigarette as observed in Table 2 and Fig. 7.

From the reduction characteristics of benzene and phenol observed from the two model cigarettes, it is evident that the treated local cigarette RR-M exhibits a high degradation of phenol as compared to the degradation of benzene. Conversely, the treated commercial (standard) cigarette MM-R has a high removal of benzene in comparison of the removal of phenol. The mechanistic processes observed herein are not well understood and should be the subject of future research. Nonetheless, the noted differences in concentrations of the model compounds among the two cigarettes are partly responsible for the observed reductions. Moreover, additives such as sugars and flavourings in commercial cigarettes are another factor that may contribute to the observed reduction in tobacco toxins. Generally, the adsorbent $(C$. megalocarpus seed husk biochar) and puff times play a critical role in the reduction of tobacco chemicals.

The rate of decay of benzene in RR-M (non-standard) cigarette is faster compared to the rate of decay of benzene in the commercial (standard) cigarette. A similar observation is registered in Fig. 5b, d, for the degradation of phenol as a function of puff time. The decay rate for both the degradation of benzene and phenol is consistent with pseudo-first-order rate law of the form shown in Eq. (4).

$$
C=\mathrm{e}^{-k t}
$$

The rate constants for the removal of benzene from treated MM-R and RR-M cigarettes were $0.123 \mathrm{~s}^{-1}$ and $0.0759 \mathrm{~s}^{-1}$, respectively, while the rate constants for the removal of phenol from the model cigarettes were $0.125 \mathrm{~s}^{-1}$ and $0.163 \mathrm{~s}^{-1}$, respectively. These results suggest that the higher the rate constant $(k)$ the easier the toxic pyrolytic tobacco by-products, in particular benzene and phenol to penetrate deeper into the lungs of the smoker, therefore causing cell damage and initiating 
malignant growth, cancers, cardiovascular diseases and serious respiratory problems such as chronic obstructive pulmonary (COPD) disease and emphysema.

In effect, longer residence times (puff times) precipitate possible side reactions which result in the conversion of benzyl and phenoxy radicals to form potentially less harmful by-products. It is well known in the literature that shorter residence times minimize secondary reactions but longer residence times may lead to radical formation and recombination (Kibet et al. 2012). Thus, these processes reduce the yield of the parent compounds, in this case, benzene and phenol inhaled by the cigarette smoker. Longer smoking times therefore, may lower the concentration of toxic molecular products reaching the lungs of the cigarette smoker, and this, ultimately may be beneficial to the cigarette smoking community.

The health risks of cigarette smoking are well known, but most diseases associated with cigarette smoking are not directly linked to the addictive nature of nicotine, considered to be relatively harmless at the levels present in tobacco by regulatory and healthcare authorities but by the toxic chemicals in mainstream cigarette smoke (Azzopardi et al. 2021). Nonetheless, the removal of tobacco chemicals in mainstream cigarette smoke, however, may present some notable challenges in the quality, organoleptic properties and psychotropic pleasure usually associated with nicotine. Reducing nicotine content in cigarette smoke therefore holds the potential for a significant impact on public health benefits especially on addiction behaviour. Ultimately, the main goal of a nicotine reduction strategy would be to minimize the addictive nature of cigarettes and promote cessation (Berman and Glasser 2019). Notably, most chemicals present in tobacco with the exception of nicotine are not addictive. For instance, the model compounds investigated in this work - phenol and benzene-are well-established human carcinogens, and if possible should be removed completely from mainstream cigarette smoke.

\section{Conclusions}

This study has demonstrated a remarkable breakthrough towards harm reduction among the cigarette smoking community by incorporating $C$. megalocarpus seed husk biocatalyst in the cigarette filter that is capable of degrading benzene and phenol in commercial cigarettes by $\sim 15$ and $11 \%$, respectively, under conditions representative of cigarette smoking. Reduction of these tobacco toxins is more pronounced at longer residence times. For instance at $15 \mathrm{~s}$ puff time, the reduction in benzene and phenol was $\sim 56$ and $37 \%$, respectively. Therefore, smoking cigarettes at longer puff times would be beneficial to the cigarette smoker. The rate constant for the degradation of benzene was higher than the rate constant for the degradation of phenol in the case of the commercial cigarette (MM-R). On the other hand, the rate of degradation of benzene and phenol from the local cigarette (RR-M) was relatively higher. However, the mechanistic processes for these observations are not well understood and this should form a basis for further studies towards harm reduction in the fight against the tobacco epidemic. Generally, high rate constants predict higher rates of destruction of molecular species in mainstream cigarette smoke. The two cigarettes investigated in this work coded MM-R and RR-M have exhibited different kinetic characteristics possibly because of their different biomass composition ascribed mainly to their growing conditions and additives introduced during tobacco processing. The destruction of phenol and benzene investigated in this work can be extended to other tobacco chemicals of concern such as nicotine, aldehydes, pyridine, nitrosamines and polycyclic aromatic hydrocarbons. This study has also established that longer puff times result in lower concentration of tobacco chemicals impinging the lungs of the cigarette smoker.

\section{Abbreviations}

C. megalocarpus: Croton megalocarpus; IARC: International Agency for Research on Cancer; ISO: International Organization for Standards; LC: Liquid chromatograph; MCS: Mainstream cigarette smoke; NTP: National Toxicology Program; UV-Vis: Ultraviolet-visible; WHO: World Health Organization.

\section{Acknowledgements}

The authors would like to recognize the assistance accorded to us by the Africa Centre of Excellence II in Phytochemicals, Textiles and Renewable Energy (ACE II PTRE) of Moi University, and Egerton University towards the success of this review paper.

\section{Authors' contributions}

AKM contributed to formal analysis and writing the original draft. JKK contributed to conceptualization, methodology, formal analysis, writing and editing, validation and supervision. FOO contributed to data curation, formal analysis, supervision and writing - review and editing. All authors read and approved the final manuscript.

Funding

This study received no specific grants from any funding agency.

Availability of data and materials

The data associated with the findings of this study are available from the corresponding author upon reasonable request.

\section{Declarations}

Ethics approval and consent to participate

Not applicable.

\section{Consent for publication}

Not applicable.

\section{Competing interests}

The authors have no competing interests.

\section{Author details}

${ }^{1}$ Department of Chemistry and Biochemistry, Moi University, Eldoret, Kenya. ${ }^{2}$ Department of Chemistry, Egerton University, Njoro, Kenya. ${ }^{3}$ African Centre of Excellence in Phytochemicals, Textiles and Renewable Energy (ACE II-PTRE), Eldoret, Kenya. 
Received: 1 November 2021 Accepted: 31 January 2022

Published online: 10 February 2022

\section{References}

Abplanalp W, DeJarnett N, Riggs DW, Conklin DJ, McCracken JP, Srivastava S, Xie Z, Rai S, Bhatnagar A, O'Toole TE (2017) Benzene exposure is associated with cardiovascular disease risk. PLoS ONE 12:e0183602

Ambaye TG, Vaccari M, van Hullebusch ED, Amrane A, Rtimi S (2021) Mechanisms and adsorption capacities of biochar for the removal of organic and inorganic pollutants from industrial wastewater. Int J Environ Sci Technol 18:3273-3294

Azzopardi D, Liu C, Murphy J (2021) Chemical characterization of tobacco-free "modern" oral nicotine pouches andtheir position on the toxicant and risk continuums. Drug Chem Toxicol 25:1-9

Bak JH, Lee SM, Lim HB (2015) Safety assessment of mainstream smoke of herbal cigarette. Toxicol Res 31:41-48

Baker RR (2006) Smoke generation inside a burning cigarette: modifying combustion to develop cigarettes that may be less hazardous to health. Prog Energy Combust Sci 32(4):373-385

Beauval N, Verrièle M, Garat A, Fronval I, Dusautoir R, Anthérieu S, Garçon G, LoGuidice JM, Allorge D, Locoge N (2019) Influence of puffing conditions on the carbonyl composition of e-cigarette aerosols. Int J Hyg Environ Health 222:136-146

Berman ML, Glasser AM (2019) Nicotine reduction in cigarettes: literature review and gap analysis. Nicotine Tob Res 21:S133-S144

Bos PMJ, Soeteman-Hernández LG, Talhout R (2021) Risk assessment of components in tobacco smoke and e-cigarette aerosols: a pragmatic choice of dose metrics. Inhal Toxicol 33:81-95

Brinkman MC, Teferra AA, Kassem NO, Kassem NOF (2020) Effect of electric heating and ice added to the bowl on mainstream waterpipe semivolatile furan and other toxicant yields. Tob Control 29:s110

Busch C, Streibel T, Liu C, McAdam KG, Zimmermann R (2012) Pyrolysis and combustion of tobacco in a cigarette smoking simulator under air and nitrogen atmosphere. Anal Bioanal Chem 403:419-430

Cai K, Gao W, Yuan Y, Gao C, Zhao H, Lin Y, Pan W, Lei B (2019) An improved in situ acetylation with dispersive liquid-liquid microextraction followed by gas chromatography-mass spectrometry for the sensitive determination of phenols in mainstream tobacco smoke. J Chromatogr A 1603:401-406

Calabuig E, Marcilla A (2021) Effect of a mesoporous catalyst on the flash pyrolysis of tobacco. Thermochim Acta 705:179032

Chaaya M, Nakkash R, Saab D, Kadi L, Afifi R (2019) Effect of tobacco control policies on intention to quit smoking cigarettes: a study from Beirut, Lebanon. Tobacco Induced Dis 17:63

Cui Y, Forget EL, Zhu Y, Torabi M, Oguzoglu U (2019) The effects of cigarette price and the amount of pocket money on youth smoking initiation and intensity in Canada. Can J Public Health 110:93-102

Ding M, Wei B, Zhang Z, She S, Huang L, Ge S, Sheng L (2017) Effect of potassium organic and inorganic salts on thermal decomposition of reconstituted tobacco sheet. J Therm Anal Calorim 129:975-984

Eaton D, Jakaj B, Forster M, Nicol J, Mavropoulou E, Scott K, Liu C, McAdam K, Murphy J, Proctor CJ (2018) Assessment of tobacco heating product THP1.0. Part 2: product design, operation and thermophysical characterisation. Regul Toxicol Pharmacol 93:4-13

Ferrero A, Espluques A, Estarlich M, Llop S, Cases A, Mantilla E, Ballester F, Iñiguez C (2017) Infants' indoor and outdoor residential exposure to benzene and respiratory health in a Spanish cohort. Environ Pollut 222:486-494

Flor LS, Reitsma MB, Gupta V, Ng M, Gakidou E (2021) The effects of tobacco control policies on global smoking prevalence. Nat Med 27:239-243

Gasparyan H, Mariner D, Wright C, Nicol J, Murphy J, Liu C, Proctor C (2018) Accurate measurement of main aerosol constituents from heated tobacco products (HTPs): implications for a fundamentally different aerosol. Regul Toxicol Pharmacol 99:131-141

Hassan N, Baharom N, Dawam ND, Ismail N, Festus E, Mihat O, Chong CK (2018) Strengthening quit smoking services in Malaysia through Malaysia Quit (mQuit) Program. Tob Induc Dis 16(1):862
Jablonski JJ, Maines JH, Cheetham AG, Gillman IG (2019) Comparative levels of carbonyl delivery between mass-market cigars and cigarettes. Regul Toxicol Pharmacol 108:104453

Jebet A, Kibet J, Ombaka L, Kinyanjui T (2017) Surface bound radicals, char yield and particulate size from the burning of tobacco cigarette. Chem Cent J 11:1-8

Jing Y, Yuan X, Yuan Q, He K, Liu Y, Lu P, Li H, Li B, Zhan H, Li G (2016) Determination of nicotine in tobacco products based on mussel-inspired reduced graphene oxide-supported gold nanoparticles. Sci Rep 6:29230

Kamissoko A, Carré V, Schramm S, Aubriet F (2019) Study of the mainstream cigarette smoke aerosols by Fourier transform ion cyclotron resonance mass spectrometry coupled to laser/desorption and electrospray ionization-additional insights on the heteroaromatic components. Rapid Commun Mass Spectrom 33:95-108

Kennedy RD, Millstein RA, Rees VW, Connolly GN (2013) Tobacco industry strategies to minimize or mask cigarette smoke: opportunities for tobacco product regulation. Nicotine Tob Res 15:596-602

Khuenkaeo N, Phromphithak S, Onsree T, Naqvi SR, Tippayawong N (2021) Production and characterization of bio-oils from fast pyrolysis of tobacco processing wastes in an ablative reactor under vacuum. PLOS ONE 16(7):e0254485

Kibet J, Khachatryan L, Dellinger B (2012) Molecular products and radicals from pyrolysis of lignin. Environ Sci Technol 46:12994-13001

Kibet JK, Khachatryan L, Dellinger B (2015) Phenols from pyrolysis and copyrolysis of tobacco biomass components. Chemosphere 138:259-265

Kibet J, Kurgat C, Limo S, Rono N, Bosire J (2016) Kinetic modeling of nicotine in mainstream cigarette smoking. Chem Cent J 10:1-9

Kibet J, Bosire J, Kinyanjui T, Lang'at M, Rono N (2017) Characterization of forest fire emissions and their possible toxicological impacts on human health. J for Environ Sci 33:113-121

King BA, Graffunder C (2018) The Tobacco Control Vaccine: a populationbased framework for preventing tobacco-related disease and death. Tob Control 27:123

Liang L, Xi F, Tan W, Meng X, Hu B, Wang X (2021) Review of organic and inorganic pollutants removal by biochar and biochar-based composites. Biochar 3:255-281

Lisko JG, Stanfill SB, Duncan BW, Watson CH (2013) Application of GC-MS/MS for the analysis of tobacco alkaloids in cigarette filler and various tobacco species. Anal Chem 85:3380-3384

Luo C, Li Y, Yang L, Wang X, Long J, Liu J (2015) Superparamagnetic iron oxide nanoparticles exacerbate the risks of reactive oxygen species-mediated external stresses. Arch Toxicol 89:357-369

Marcilla A, Gómez-Siurana A, Berenguer D, Martínez-Castellanos I, Beltrán MI (2015) Reduction of tobacco smoke components yield in commercial cigarette brands by addition of HUSY, NaY and AI-MCM-41 to the cigarette rod. Toxicol Rep 2:152-164

Marcilla A, Beltran MI, Gómez-Siurana A, Berenguer D, Martínez-Castellanos I (2016) Nicotine/mesoporous solids interactions at increasing temperatures under inert and air environments. J Anal Appl Pyrol 119:162-172

Murniati R, Sutisna, Wibowo E, Rokhmat M, Surtiyeni N, Yuliza E, Khairurrijal, Abdullah M (2015) Reduction of harmful substances in cigarette smoke using $\mathrm{TiO}_{2}$ nanoparticles. In: Kolisnychenko S (ed) Advanced materials research, vol 1112. Trans Tech Publications Ltd., Freienbach, pp 425-428

Ren J, Li B, Yu D, Liu J, Ma Z (2016) Approaches to prevent the patients with chronic airway diseases from exacerbation in the haze weather. J Thorac Dis 8:E1-7

Rodriguez-Acevedo AJ, Green AC, Sinclair C, van Deventer E, Gordon LG (2020) Indoor tanning prevalence after the International Agency for Research on Cancer statement on carcinogenicity of artificial tanning devices: systematic review and meta-analysis. Br J Dermatol 182:849-859

Schubert J, Müller FD, Schmidt R, Luch A, Schulz TG (2015) Waterpipe smoke: source of toxic and carcinogenic VOCs, phenols and heavy metals? Arch Toxicol 89:2129-2139

Shen J, Li J, Qian X, Ren W, Fatehi P (2014) A review on engineering of cellulosic cigarette paper to reduce carbon monoxide delivery of cigarettes. Carbohydr Polym 101:769-775

Shifflett JR, Watson L, McNally DJ, Bezabeh DZ (2017) Analysis of the polyphenols of tobacco using pressurized liquid extraction (PLE) and ultra performance liquid chromatography with electrospray ionization-tandem 
mass spectometric detection (UPLC-ESI-MS/MS). Contrib Tob Res 27:195-207

Song MA, Benowitz NL, Berman M, Brasky TM, Cummings KM, Hatsukami DK, Marian C, O'Connor R, Rees VW, Woroszylo C, Shields PG (2017) Cigarette filter ventilation and its relationship to increasing rates of lung adenocarcinoma. J Natl Cancer Inst 109:djx075

Sun Y, Gao B, Yao Y, Fang J, Zhang M, Zhou Y, Chen H, Yang L (2014) Effects of feedstock type, production method, and pyrolysis temperature on biochar and hydrochar properties. Chem Eng J 240:574-578

Takaya CA, Fletcher LA, Singh S, Anyikude KU, Ross AB (2016) Phosphate and ammonium sorption capacity of biochar and hydrochar from different wastes. Chemosphere 145:518-527

Tan X, Liu Y, Zeng G, Wang X, Hu X, Gu Y, Yang Z (2015) Application of biochar for the removal of pollutants from aqueous solutions. Chemosphere 125:70-85

Tomczyk A, Sokołowska Z, Boguta P (2020) Biochar physicochemical properties: pyrolysis temperature and feedstock kind effects. Rev Environ Sci Biotechnol 19:191-215

Wright C (2015) Standardized methods for the regulation of cigarette-smoke constituents. TrAC Trends Anal Chem 66:118-127

\section{Publisher's Note}

Springer Nature remains neutral with regard to jurisdictional claims in published maps and institutional affiliations.

\section{Submit your manuscript to a SpringerOpen ${ }^{\odot}$ journal and benefit from:}

- Convenient online submission

- Rigorous peer review

- Open access: articles freely available online

- High visibility within the field

- Retaining the copyright to your article

Submit your next manuscript at $\boldsymbol{\nabla}$ springeropen.com 